\title{
SIMULAÇÃO DO USO DA ENTOMOLOGIA PARA ESTIMAR O INTERVALO PÓS-MORTE
}

\author{
Marcelo Fruehwirth ${ }^{1}$, Rafaela de Araujo Folha ${ }^{2}$ \\ ${ }^{1}$ Faculdade Assis Gurgacz - FAG, Cascavel, PR. ${ }^{1,2}$ Universidade Estadual do Oeste do Paraná - UNIOESTE, Centro de \\ Ciências Médicas e Farmacêuticas CCMF , Cascavel, PR. E-mail: marcelo_fru@hotmail.com
}

\section{RESUMO}

Diversos tipos de insetos podem colonizar a matéria orgânica, acelerando assim os fenômenos cadavéricos transformativos. Por meio de estudos sobre esses animais, podem ser obtidas as características da morte ou até mesmo a causa. Foram utilizados dois porcos Sus domesticus (Erxleben 1777), sendo um animal exposto ao ambiente e outro enterrado, ambos por 25 dias. A simulação se baseou em uma perícia de local de crime realizada em Cascavel-PR, onde os peritos não saberiam das condições da cena. Analisando o estado das carcaças, concluiu-se que a carcaça 1 estaria a cerca de 20 a 25 dias no local, e a carcaça 2 de 15 a 18 dias. Os dados obtidos por meio da amostra coincidem com o tempo de exposição do animal ao ambiente, porém, não foi possível datar o tempo exato de morte utilizando os dados entomológicos.

Palavras-Chave: porcos, insetos, perícia, crime, simulação.

\section{A SIMULATION OF THE USE OF ENTOMOLOGY AS AN AID TO ESTIMATING THE POSTMORTEM INTERVAL}

\section{ABSTRACT}

Several types of insects can colonize organic matter, accelerating rotting corpse. Through studies of these animals, it can be obtained from the characteristics of death or even the cause. We used two pigs Sus domesticus (Erxleben 1777), being an animal exposed to the environment and other buried, both for 25 days. The simulation was based on a crime scene forensics held in Cascavel city, Paraná, where the experts do not know the conditions of the scene. Analyzing the cadaverous state, it was found that the carcass 1 would have about 20 to 25 days on site, and the carcass 2 about 15 to 18 days. The data obtained through the sample match the exposure time of the animal to the environment, however, it has not been possible to date the accurate time of death using the entomological data.

Keywords: pigs, insects, forensics, crime, simulation.

\section{INTRODUÇÃO}

A morte dá início a uma série de transformações físico-químicas que fazem parte de um processo de decomposição. A partir disso formar-se-ão diversos produtos derivados líquidos ou voláteis, sendo estes, atrativos para a fauna entomológica existente no local ${ }^{1,2,3}$.

Os meios disponíveis aos profissionais da área forense permitem estimar com certa garantia o tempo de morte recente, em até 48 horas. No entanto, o tempo de morte tardio exige mecanismos investigativos mais complexos e por vezes, adicionalmente, informações oferecidas por elementos extra-corporal ${ }^{4}$. É justamente nesse campo que pode se inserir a Entomologia Forense ${ }^{5}$.
Diversos tipos de insetos podem colonizar a matéria orgânica, acelerando assim os fenômenos cadavéricos transformativos, e através de estudos sobre esses animais, podem ser obtidas as características da morte, como o intervalo de pós-morte ou até mesmo a causa. Assim, a fauna entomológica é de fundamental importância para a criminalística, uma vez que a entomologia forense pode esclarecer diversos $\operatorname{casos}^{5,6}$

Segundo Neves ${ }^{7}$, o entendimento do processo de decomposição cadavérica é de suma importância para a aplicação da entomologia nos casos forenses.

O objetivo do presente trabalho foi estimar o intervalo de pós-morte de uma carcaça 
em avançado estado de decomposição por meio de suas características físicas e da entomofauna, estipulando um padrão entomológico.

\section{METODOLOGIA}

As carcaças

Para a simulação, foram utilizados dois porcos Sus domesticus (Erxleben 1777) inteiros, com peso médio de $15 \mathrm{~kg}$, comprados em um frigorífico localizado na cidade de Cascavel-PR e abatidos por um golpe de faca (punhal) no coração. Esses animais foram dispostos em um terreno pertencente ao Centro Universitário Assis Gurgacz, localizada na Avenida das Torres, no 500 - Bairro FAG - Cascavel/PR. As coordenadas geográficas do local são: Latitude $24^{\circ} 56^{\prime} 47.77^{\prime \prime} \mathrm{S}$ e Longitude $53^{\circ} 30^{\prime} 39.81^{\prime \prime} \mathrm{O}$, com altitude de aproximadamente 709 metros, sendo um suíno enterrado e outro enrolado completamente em uma camiseta ficando exposto ao tempo mas cercado por uma grade de proteção, com uma distancia de 2 metros entre eles.

Todos os procedimentos realizados foram autorizados pela instituição, que dispôs de um funcionário para isolamento da área e averiguação do perímetro para que não houvesse interferência de estranhos. Os corpos foram deixados por 25 dias sem interferência humana.

A simulação se baseou em uma perícia de local de crime, onde 8 peritos verificaram as cenas simultaneamente. A partir deste pretexto, deu-se inicio a investigação.

\section{Características do local de acordo com a perícia}

O local tratava-se de um ambiente aberto, cercado por floresta tropical fechada. A carcaça estava posicionada no solo em local aberto, parcialmente sombreado pelas árvores, sem lagos ou córregos nas proximidades, estando, portanto, o solo pouco úmido no momento da perícia. Além do viveiro de araras ao lado dos corpos, algumas construções encontravam-se nos arredores.

A temperatura no momento da perícia era de $26{ }^{\circ} \mathrm{C}$, entretanto, deve-se considerar a média de temperatura registrada nos dias anteriores, uma vez que o processo de decomposição é afetado pela temperatura e umidade. Desta forma, a média de temperatura máxima dos 14 dias antecedentes era de $28,5{ }^{\circ} \mathrm{C}$ e mínima de $11,2{ }^{\circ} \mathrm{C}$. A média da taxa de umidade relativa do ar dos 14 dias antecedentes era de $52 \%$, não havendo precipitação no local.
Materiais para coleta de amostras

Os materiais utilizados para realizar a coleta foram pinças, água aquecida, potes plásticos para armazenamento das amostras coletadas, sacos para material biológico, álcool $70 \%$ e uma rede entomológica. Todos os materiais com exceção da rede entomológica foram previamente esterilizados. Segundo Mégnin ${ }^{8}$, o perito deve estar bem equipado na hora da coleta, com materiais estéreis e licenciados, previamente testados e seu uso autorizado.

A metodologia utilizada para a coleta do material foi baseada na descrita por Paradela e Paradela ${ }^{9}$, sendo ela introduzida junto às particularidades de cada perito.

Procedimentos metodológicos adotados pelos peritos

Os procedimentos iniciais foram 0 isolamento do local, a fim de evitar degradação das características originais encontradas no ambiente $^{10}$. Posteriormente, fotografou-se todo o local e adjacências, além do corpo de forma a enfatizar todos os detalhes. A próxima etapa foi descrever as características locais e também do cadáver encontrado para confecção posterior do laudo pericial.

A temperatura do local foi medida durante a coleta utilizando um termômetro digital da marca Western ${ }^{\circledast}$.

Coletaram-se amostras entomológicas da fauna cadavérica e também de larvas presentes no solo próximo ao corpo com o auxílio de pinças. Com a rede entomológica, foram capturados insetos que sobrevoavam os corpos. Enfatiza-se que se devem tomar cuidados na hora da coleta entomológica, pois o intervalo pós-morte (IPM) será calculado através dos insetos ${ }^{11}$.

As amostras coletadas foram levadas até o laboratório de Zoologia do Centro Universitário Assis Gurgacz para efetuar a classificação e a pesagem da massa entomológica, a fim de identificar as espécies e seu tempo de vida, prosseguindo com a determinação do intervalo pós-morte do cadáver encontrado.

\section{RESULTADOS}

Descrição das carcaças segundo a perícia As carcaças foram identificados previamente como 1 e 2, para melhor compreensão do laudo. A carcaça 1 fora encontrada totalmente desfigurada, em fase coliquativa de decomposição, não foi possível 
identificar nenhum ferimento devido ao estágio em que se encontrava; A carcaça estava em posição horizontal e inserida em uma cova de cerca de $0,90 \mathrm{~cm}$ por $0,55 \mathrm{~cm}$ e profundidade de aproximadamente $0,45 \mathrm{~cm}$.

A carcaça 2 foi encontrada com características de pele se desprendendo do corpo, aspecto mole, em avançado estado de putrefação, passando da fase gasosa para coliquativa. O indivíduo possuía coloração de pele branca com manchas escuras no corpo, manchas que pelo tempo de exposição poderiam não ser características do animal. A carcaça possuía uma cicatriz abdominal e um ferimento do lado esquerdo da região peitoral, de aproximadamente $7 \mathrm{~cm}$, localizado próximo às axilas, provavelmente ocasionado por um golpe de faca, além de um hematoma do lado superior esquerdo na região da escápula. O corpo possuía cerca de $65 \mathrm{~cm}$ de comprimento, e encontrava-se sobre o solo, exposto às condições ambientais que aceleraram sua decomposição. Além disso, o corpo se apresentava com suas vestes, havendo presença de larvas nos orifícios do corpo, bem como odor sui generis.

\section{Entomofauna coletada}

Na carcaça 1 foram encontradas 24 larvas da família Calliphoridae mesmo estando completamente sob o solo. Na carcaça 2 foram coletadas 198 larvas vermiformes, em sua maioria típicas de moscas da família Calliphoridae e Muscidae ${ }^{7}$ encontradas principalmente nos orifícios (boca, ânus e o ferimento localizado próximo a axila) que estava exposto ao ambiente (Figura 1). Além das larvas, foram encontradas 12 pupas pertencentes à família Calliphoridae e quatro exemplares de besouros pertencentes à família Coprophanaeus.

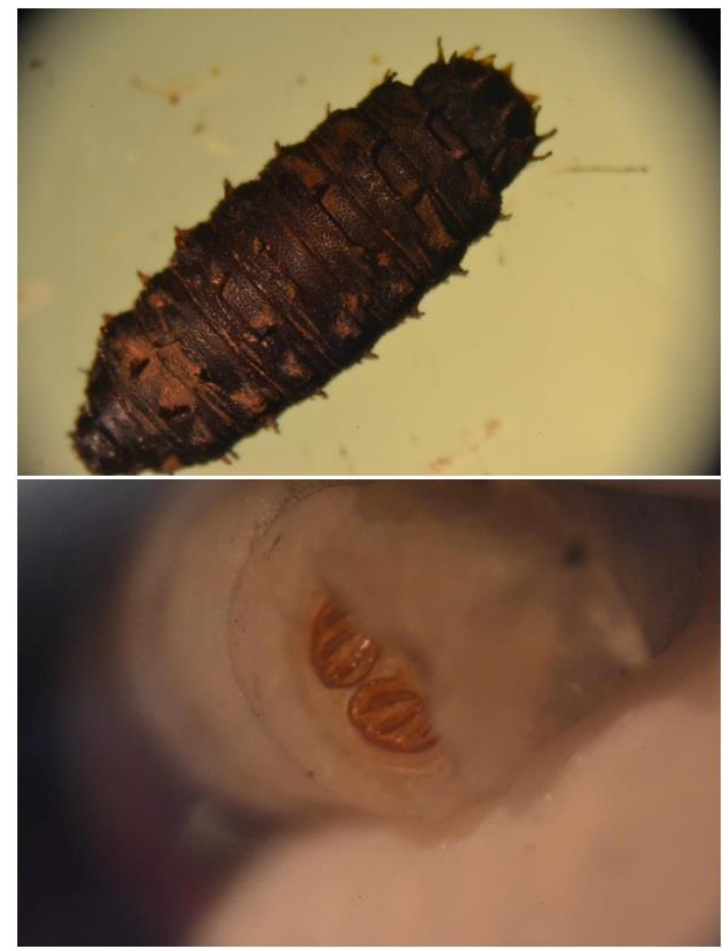

Figura 1. Superior: larva da espécie $D$. hominis em instar 3. Inferior: pupa encontrada no orifício anal do indivíduo 2. Visualização em lupa macroscópica.

Com a rede entomológica, foi possível coletar alguns insetos importantes para a identificação. Um deles é uma Mosca-Varejeira, pertencente à família Calliphoridae adulta, que estava sobre a carcaça 2. Em literatura há descrição de 35 espécies de Calliphoridae encontradas no Brasil, distribuídas em todas as regiões, o que as torna importantes para identificação do local de morte ${ }^{12}$. Outra encontrada é uma Dermatobia hominis, também adulta e, por ultimo, vários exemplares da Musca domestica, conhecida como Mosca Comum.

Entre os insetos presentes no cadáver, os necrófagos representam papel fundamental para tal finalidade. Os insetos, especialmente da Ordem Díptera, possuem órgãos sensitivos altamente especializados e podem perceber os odores exalados pelos cadáveres, carcaças e restos mortais muito antes de poderem ser percebidos pelos humanos ${ }^{13}$. 
Os dípteros da família Calliphoridae podem ser considerados um dos grupos de insetos mais comuns do mundo, tendo em vista sua ampla distribuição e por ocorrerem nos mais diferentes ambientes ${ }^{14}$. Apesar dos califorídeos serem amplamente distribuídos e muito abundantes, quando comparada com outras famílias como Oestroidea, possui um número bem menor de espécies.

As espécies de Calliphoridae, exceto as da subfamília Mesembrenellinae, são moscas de coloração escura com reflexos metálicos azulados, esverdeados, violáceos ou cúpricos, principalmente no abdome $e^{15,16}$.

Para se calcular o IPM utilizou-se do cálculo preconizado por Oliveira-Costa ${ }^{4}$ que utiliza o grau-dia acumulado (GDA), em que por meio da temperatura, relaciona os dados do desenvolvimento das espécies criadas em laboratório com as condições ambientais normais ${ }^{17}$. Por não haver dados em literatura sobre 0 desenvolvimento das moscas encontradas na região de estudo, o índice GDA foi baseado em literatura ${ }^{18}$, porém pelas características das carcaças foi possível estimar um tempo de morte mais aproximado da realidade do que com o uso da entomofauna, o que a tornou obsoleta para este caso.

\section{DISCUSSÃO}

A postura de ovos no cadáver marca o início de um relógio biológico que é usado por entomólogos forenses. Dois métodos podem ser utilizados: 1) a estimativa da idade dos insetos imaturos que se alimentam do cadáver, de acordo com seu grau de desenvolvimento e 2) a análise da comunidade de insetos presentes ${ }^{19}$.

Moscas varejeiras são as principais espécies usadas para estimar o IPM e são normalmente as primeiras a colonizar um organismo. A duração do desenvolvimento das formas imaturas mais antigas encontradas no corpo, ou no local do crime é usada para calcular intervalo pós-morte ${ }^{20,21}$.

As moscas passam por três fases principais de desenvolvimento, a saber: o ovo, a larva e a pupa, que constituem entre $3-7 \%$, 25$57 \%$ e $35-69 \%$ do tempo total de desenvolvimento, respectivamente. A duração do desenvolvimento do período larval é conseguida, principalmente, pela medição do tamanho das larvas, por exemplo, comprimento ou peso, e muda larval primeiro, segundo e terceiro ínstar. Existem vários métodos que têm sido utilizados para estudar o desenvolvimento da pupa numa tentativa de aperfeiçoar as estimativas do IPM $^{20,22,23}$.

\section{O tempo de morte}

O tempo de morte dos indivíduos foi deduzido com base nas informações adquiridas com o auxílio da fauna entomológica e o estado cadavérico. Segundo descrito por Barnes ${ }^{24}$, a mosca-varejeira leva aproximadamente $24 \mathrm{~h}$ para que os seus ovos eclodam, transformando-os em larvas de primeiro instar. Para que as larvas de primeiro instar cheguem ao instar 3 são necessários aproximadamente $50 \mathrm{~h}$, levando em consideração que seu ciclo depende do clima da região, umidade do ar e sua alimentação, podendo ser variável. Para que a larva de instar 3 se desenvolva a pupa, são necessários aproximadamente $130 \mathrm{~h}$, o que totaliza uma média de 8 dias desde a disposição dos ovos sobre o cadáver. Não foram encontradas pupas eclodidas.

Já com relação ao cadáver, a fase coliquativa consiste na dissolução pútrida do cadáver ou deliquescência cadavérica, com a desintegração das partes moles, redução de volume, deformação, liberação dos gases e inúmeras larvas, de cronologia variável, com início de três semanas após o óbito ${ }^{25}$.

A fase gasosa é caracterizada pelo aumento progressivo e rápido da produção de gases pelas bactérias, que se disseminam por todos os tecidos dando origem a um enfisema subcutâneo. Em consequência desse acúmulo de gases, o corpo vai ficando com aspecto gigantesco, com os olhos e língua proeminentes. Ainda nesta fase, a grande produção de líquidos, que migram para a superfície dá origem a bolhas (flictenas putrefativas) de tamanhos variados, nos tegumentos, local aonde a epiderme vai se destacando deixando a derme exposta ${ }^{26}$.

O GDA esperado para espécies de Mosca Varejeira se aproxima de 158,78 em uma temperatura média de $27^{\circ} \mathrm{C}$ com umidade relativa de $70 \%$ no local, e o tempo médio de desenvolvimento em dias é de $9,34^{18}$.Com base neste estudo, já que a temperatura em média foi parecida, os peritos puderam afirmar que as carcaças se encontravam no local por no mínimo 8 dias, porém, não era compatível com o estado de putrefação das carcaças. Essa divergência provavelmente se dá pelas condições ambientais, já que a variação de temperatura, umidade e 
exposição ao sol, por exemplo, podem interferir diretamente nas fases de decomposição e na colonização por insetos.

Martins et al. ${ }^{11}$ utilizou-se do método GDA para calcular o tempo de morte de um Canis lupus familiaris, porém, houve divergências com o tempo real de exposição, tornando-o inconclusivo. Leal et al. ${ }^{17}$ demonstrou que 0 calculo pode ser útil dependendo das informações adicionais que os peritos venham a ter, e não somente os dados encontrados na cena de crime.

\section{CONCLUSÃO}

O IPM não foi condizente com o tempo real de exposição, pois o calculo GDA não pode ser utilizado com exatidão, devido à escassez de dados sobre o desenvolvimento das larvas em laboratório na temperatura e umidade idênticas a do local de crime. Já utilizando os dados entomológicos, os peritos afirmaram que o corpo estaria a no mínimo 8 dias ao tempo, porém, esta informação não foi útil devido ao estado de putrefação do cadáver, que já evidenciava seu tempo maior no local. Contudo, ressalta-se a importância desta técnica a fim de auxiliar em casos mais complexos. Novos trabalhos se fazem necessários a fim de fomentar dados sobre as espécies de insetos e seu desenvolvimento na região oeste do Paraná, auxiliando assim os futuros peritos na resolução de casos.

\section{CONFLITO DE INTERESSE}

Os autores declaram não haver qualquer potencial conflito de interesse que possa interferir na imparcialidade deste trabalho cientifico.

\section{REFERÊNCIAS}

1. Pinheiro DS, Reis AAS, Jesuíno RSA, Silva HMV. Variáveis na estimativa do intervalo pós-morte por métodos de entomologia forense. Enciclopédia Biosfera, Centro Científico Conhecer - Goiânia. 2012;8(14):1442.

2. Neto AP, Carvalo EC, Cavallari ML, Gianvecchio VAP, Neto JS, Tartarella MA, et al. Estimativa de tempo de morte por meio da entomofauna cadavérica em cadáveres putrefeitos: Relato de Caso. Saúde, Ética \& Justiça. 2009;14:92-6. DOI: https://doi.org/10.11606/issn.2317-

\section{0.v14i2p92-96}

3. França GVF. Medicina Legal. 8.ed. Rio de Janeiro: Guanabara-Koogan; 2008. p.629.
4. Oliveira-Costa J. Entomologia Forense - quando os insetos são vestígios. 2.ed São Paulo: Millennium; 2007. P.167-264.

5. Martins E. Análise dos processos de decomposição e sucessão ecológica em carcaças de suíno (Sus scrofa I.) mortos por disparo de arma de fogo e overdose de cocaína e protocolo de procedimento diante de corpo de delito. [Tese]. Universidade Estadual Paulista (Unesp Botucatu), 2009.

6. Carvalho ECT, Queiroz, PR. Descrição das principais famílias de díptera utilizadas na entomologia forense. Biociências forenses. 2013.

7. Neves DP, Melo AL, Linardi PM, Vitor RWA. Parasitologia humana. 11.ed. São Paulo: Editora Atheneu; 2005.

8. Mégnin J. La Faune dês cadáveres: applicationde l'entomologie a la medicine legale. Paris: Encyclopedie Scientifique dos Aides, Memoires Masson. 1894:234.

9. Paradela Filho O, Paradela AL. O complexo Colletotrichum: cafeeiro. In: Zambolim L. (Ed.). Tecnologias de produção de café com qualidade. Viçosa, UFV, Departamento de Fitopatologia. 2001;8:269-75.

10. Lee HC, Bourke M. Crime scene investigation. Central Police University Press; 1994.

11. Martins G, Santos WE, Creão-Duarte AJ, da Silva LBG, Oliveira AAF. Estimativa do intervalo pós-morte em um canino (Canis lupus familiaris Linnaeus 1758) pela entomologia forense em Cabedelo-PB, Brasil: relato de caso. Arq Bras Med Vet Zootec. 2013;65(4)1107-10. DOI: https://doi.org/10.1590/S0102-

\section{4}

12. Faver F. Medicina legal. 12.ed. São Paulo: Villa Rica; 1992. p.587-604.

13. Catts EP, Goff ML. Forensic entomology in criminal investigations. Ann Rev Entomol. 1992;27:253-72.

DOI: https://doi.org/10.1146/annurev.en.37.010192.0 $\underline{01345}$

14. Erzinçlioglu Z. Bowflies. Slough. London: The Richmond Publishing Co. Ltd; 1996. p.71.

15. Buzzi JZ. Coletânea de nomes populares de insetos do Brasil.. Curitiba: Edição do autor; 1994. p.230.

16. Lenko K, Papavero N. Insetos no folclore. 2.ed. São Paulo: Plêiade/FAPESP; 1996. p.468.

17. Leal JLF, Oliveira TC, Carneiro SCAS, Santos $A B R$, Vasconcelos BCE. Estimativa do Intervalo pós-morte em cadáveres congelados através da Entomologia. Rev Cir Traumatol Buco-Maxilo-Fac. 2013;13(3):41-8. 
18. Pujol-Luz JR, Arantes LC, Constantino R. Cem anos da Entomologia forense no Brasil (19082008). Rev Bras Entomol. 2008;52:485-92. DOI: https://doi.org/10.1590/S0085-

56262008000400001

19. Castro CBP. Seasonal carrion Diptera and Coleoptera communities from Lisbon (Portugal) and the utility of forensic entomology in legal medicine [tese]. Lisboa: Universidade de Lisboa, Faculdade de Ciências; 2011.

20. Richards CS, Simonsen TJ, Abel RL, Hall MJ, Schwyn DA, Wicklein $M$. Virtual forensic entomology: improving estimates of minimum post-mortem interval with 3D micro-computed tomography. Forensic Sci Int. 2012;220(1-3):25164.

DOI:

http://dx.doi.org/10.1016/i.forsciint.2012.03.012 21. Saks MJ, Koehler JJ. The coming paradigm shift in forensic identification science. Science. 2005;309(5736):892-5.

DOI:

http://dx.doi.org/10.1126/science.1111565

22. Smith KGV. A manual of forensic entomology. Ithaca, NY, USA: Cornell University Press; 1986. p.205.

23. Santos A. Tanatologia forense. Porto: Faculdade de Medicina da Universidade do Porto. 2003.

24. Barnes RD. Zoologia dos invertebrados. In: Zoologia dos invertebrados. São Paulo: Roca; 1984.

25. Aquino JRF, Cruz MJM. Os riscos ambientais do cemitério do Campo Santo, Salvador, Bahia, Brasil. Cad Geociên. 2010;7(1):19-30.

26. Amendt J, Krettek R, Zehner R. Forensic Entomology. Naturwissens-chaften. 2004;91:5265. DOI: http://dx.doi.org/10.1007/s00114-0030493-5

Recebido para publicação em 28/08/2015

Revisado em 24/05/2017

Aceito em 30/05/2017 